\title{
Alat Pengaman Koper Menggunakan GPS Berbasis Mikrokontroler Dengan Output SMS

\author{
Nadia Alfitri ${ }^{1}$, Laxsmy Devy ${ }^{2}$, Yulia Futri Utami ${ }^{3}$ \\ ${ }^{123}$ Jurusan Teknik Elektro Politeknik Negeri Padang \\ nadianalfitri@pnp.ac.id
}

\begin{abstract}
Suitcases are one of the tools that are often used to store various valuables when traveling, therefore the suitcase becomes very vulnerable to become a crime. The safety of a suitcase that is still standard causes the suitcase to easily become a target of crime, and therefore made luggage security tools with GPS based microcontroller with SMS output. This luggage safety device utilizes the google maps application to track the whereabouts of the suitcase. These coordinates will be sent via SMS to the user and the user can track where the suitcase is located. The coordinates are sent via SMS and can be tracked via google maps using android. Devices used Ublox NEO 6M GPS module determines the coordinates of the suitcase position, SIM900 module as a data sender in the form of SMS, a limit switch sensor to determine the suitcase in an open state.
\end{abstract}

Keywords: Limit switch sensor, Ublox NEO 6M, SIM900, Android Smartphone.

\begin{abstract}
Abstrak - Koper merupakan salah satu alat yang sering digunakan untuk menyimpan berbagai barang berharga pada saat berpergian,oleh karena itu koper menjadi sangat rentan untuk menjadi tindak kejahatan.Keamanan koper yang masih standart menyebabkan koper dengan mudahnya menjadi sasaran tindak kejahatan,maka dari itu dibuatlah alat keamanan koper dengan GPS berbasis mikrokontroler dengan output SMS. Alat pengaman koper ini memanfaatkan aplikasi google maps untuk melacak keberadaan koper.Titik koordinat tersebut akan dikirimkan melalui SMS kepada user dan user bisa melacak dimana koper tersebut berada.Titik koordinat yang dikirimkan melalui SMS dan dapat dilacak melalui google maps dengan menggunakan android.Perangkat yang digunakan modul GPS Ublox NEO 6M sebagai penentu koordinat posisi koper,modul SIM900 sebagai pegirim data dalam bentuk SMS,sensor limit switch untuk menentukan koper dalam keadaan terbuka.
\end{abstract}

Kata kunci: Sensor limit switch, Modul GPS Ubox NEO 6M, SIM900, Smartphone Android.

C) 2017 Elektron Jurnal Ilmiah

\section{Pendahuluan}

Koper (Travel bag) adalah tempat untuk menyimpan barang bawaan saat kita berpergian. Banyaknya pengguna meletakan barang berharga kedalam koper tanpa pengamanan, menyebabkan koper rentan menjadi target tindak kriminal pencurian. Tindak kriminal seperti pencurian biasanya terjadi di transportasi umum seperti kereta api. Seperti kasus yang terjadi di kereta api Purwerejo tas seorang penumpang dibawa kabur oleh pelaku (Detik.com) dan juga kasus yang terjadi di kereta api jurusan Gambir-Cilacap. Pelaku mencuri laptop dan handphone, pelaku mengganti laptop dengan HVS sehingga korban tidak sadar dia telah menjadi korban pencurian. Pembuatan sistem pengamanan koper telah dilakukan pada beberapa penelitian sebelumnya. Pada penelitian pertama, yang dilakukan oleh Darmayanti dari Politeknik Negeri Sriwijaya dengan menggunakan teknologi RFID, alat tersebut bisa memantau item yang ada pada tas tersebut, menggunakan smart lock, dan menggunakan GPS untuk memantau keberadaan tas tersebut. Penelitian kedua dilakukan leh Dayu Lestari dari Palembang membahas tentang pengamanan koper dengan sensor LDR yang mengindikasikan koper tersebut terbuka dan kemudian dikirimkan SMS kepada user bahwa koper tersebut telah dibuka oleh orang lain, penelitian ketiga dilakukan oleh Muhammad Athend dari Universitas Andalas membahas tentang pengamanan koper menggunakan bluetooth yang mana pada saat koper berada jauh dari jangkauan jarak yang sudah ditentukan akan dikirimkan SMS kepada user bahwa koper tersebut berada diluar jangkauan area. Berdasarkan uraian masalah diatas maka pada penelitian ini dikembangkan prototype pengamanan koper menggunakan GPS berbasis mikrokontroler dengan output SMS. Tujuan penelitian ini adalah bagaimana merancang pengamanan koper menggunakan GPS dengan notifikasi SMS serta mengetahui kordinat koper pada aplikasi android di smartphone.

\section{Metode Penelitian}

Secara keseluruhan alat ini tersusun atas bagianbagian penting yang saling berhubungan satu sama lain yaitu perangkat keras (hardware) dan perangkat lunak (software). Kedua bagian ini harus saling sinkron satu sama lain agar maksud dan tujuan dari pembuatan alat ini tercapai dan sesuai dengan yang diharapkan. Bagian hardware terdiri dari rangkaian modul SIM900, rangkaian modul GPS dan rangkaian secara keseluruhan, sedangkan bagian software terdiri dari flowchart dan program.

\subsection{Blok Diagram}

Alat keamanan koper menggunakan GPS berbasis mikrokontroler dengan output SMS ini terdiri dari beberapa blok yang saling berhubungan satu sama lainnya yang terdiri dari input, proses maupun output. 


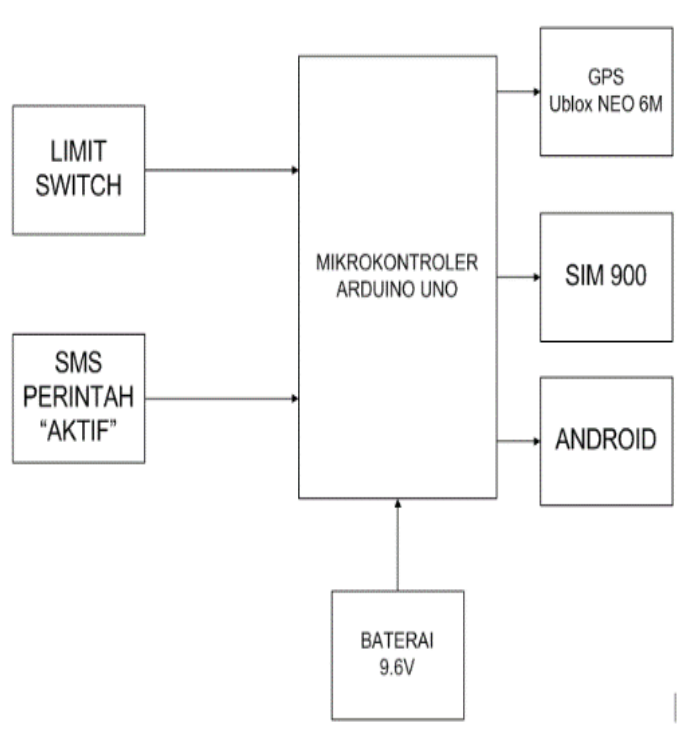

Gambar 1. Blok Diagram Alat Pengaman Koper

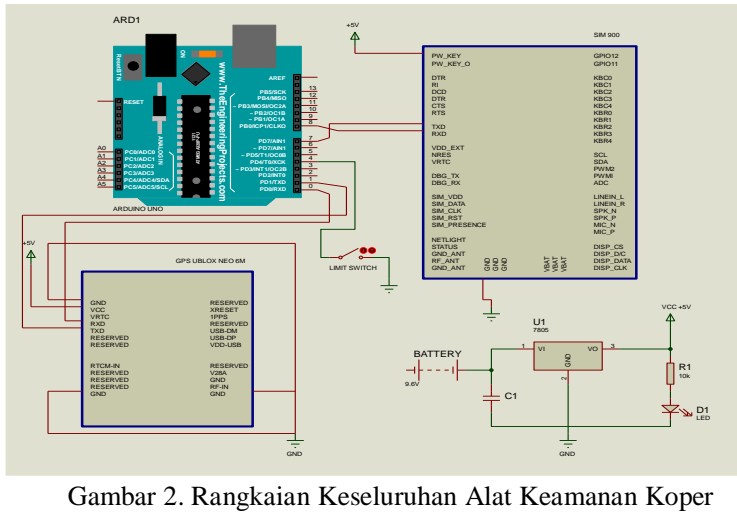

Rangakaian shield mikrokontroler ini digunakan sebagai pengendali sistem secara keseluruhan sekaligus dibuat untuk menjaga atau sebagai pelindung agar pinpin pada mikrokontroler Arduino Uno tetap terjaga dengan baik dan tidak mudah rusak. Rangkaian shield ini terhubung dengan pin RX, TX, Analog, Digital, 5V, Ground dan lain-lain yang akan dihubungkan dengan

Pada dasarnya Alat pengamanan koper konektor-konektor pada baterai, sensor limit switch, menggunakan GPS berbasis mikrokontroler dengan modul SIM900 dan modul GPS Ublox NEO 6M. Modul output SMS ini menggunakan modul SIM900 sebagai GSM yang akan digunakan adalah modul SIM900. input untuk mengaktifkan Alat.Alat sistem keamanan Modul SIM900 berfungsi untuk mengirim data SMS ke koper ini akan bekerja saat user mengirimkan SMS android. Pada modul SIM900 terdapat 4 pin yang akan dengan kata kunci "AKTIF". Pada alat ini terdapat Limit dihubungkan dengan mikrokontroler, yaitu pin VCC Switch pada bagian resleting koper.Pada saat resleting modul SIM900 terhubung ke pin 5V mikrokontroler, pin koper dibuka maka Limit Switch akan berlogikan 0 dan GND modul SIM900 terhubung ke pin GND secara otomatis modul SIM900 yang terdapat pada alat mikrokontroler, pin RX modul SIM900 terhubung ke pin akan mengirimkan data melalui SMS bahwa koper 8 mikrokontroler dan pin TX modul SIM900 terhubung dalam keadaan terbuka dan sekaligus akan mengirimkan ke pin 7 mikrokontroler. Modul GPS yang akan koordinat posisi koper. Pada alat ini juga terdapat modul digunakan adalah modul GPS Ublox NEO 6M.Modul GPS U-blox NEO 6M yang berfungsi sebagai penentu GPS berfungsi sebagai pengirim data koodinat posisi koordinat posisi koper. Pada saat koper dalam keadaan keberadaan koper. Modul GPS akan aktif dengan tertutup dan limit switch berlogikan 1, user masih bisa tegangan tegangan input $5 \mathrm{~V}$ yang dihubungkan ke pin melacak koordinat posisi koper berada.User akan 5V dan ground ke pin GND pada arduino.Selain pin mengirimkan SMS dengan kata kunci "LACAK" maka VCC dan pin GND modul GPS juga menggunakan 2 pin alat tersebut akan memberikan SMS balasan berupa titik lainnya yaitu RX dan TX. Pin RX pada modul GPS ini koordinat keberadaan koper tersebut.Dan titik koordinat akan terhubung dengan pin 1 sedangakan pin TX akan yang dikirim melalui SMS dapat diakses oleh use terhubung dengan pin 0 pada arduino. Konfigurasi pin melalui aplikasi google maps yang ada pada pin pada tiap komponen dari limit swith,modul SIM900 smartphone.Agar alat ini lebih efisien maka digunakan dan Modul GPS Ubox NEO 6M terhubung satu sama Switch pada alat tersebut untuk menyambung dan lain sesuai dengan pin yang telah digunakan. memutuskan daya pada alat.

Konfigurasi pin-pin tersebut dapat dilihat pada tabel 1.

\subsection{Perancangan hardware}

Rangkaian keseluruhan dari blok diagram suatu rangkaian tersebut akan menghasilkan suatu sistem yang dapat difungsikan sehingga dapat bekerja sesuai dengan perancangan yang telah dibuat. Gambar 2 merupakan skema diagram dari sistem rangkaian keseluruhan

\begin{tabular}{ccc}
\multicolumn{2}{c}{ Tabel.1 Konfigurasi PIN pada rangkaian } \\
\hline Modul & $\begin{array}{c}\text { PIN yang } \\
\text { digunakan }\end{array}$ & Keterangan \\
& RX & $\begin{array}{c}\text { RX ke PIN 7 } \\
\text { arduino }\end{array}$ \\
\cline { 2 - 3 } SIM900 & TX & $\begin{array}{c}\text { TX ke PIN 8 } \\
\text { arduino }\end{array}$ \\
\cline { 2 - 3 } & GND & $\begin{array}{c}\text { GND ke PIN } \\
\text { GND arduino }\end{array}$ \\
\cline { 2 - 3 } & VCC & $\begin{array}{c}\text { VCC ke PIN } \\
\text { 5V arduino }\end{array}$ \\
\hline $\begin{array}{l}\text { GPS Ublox } \\
\text { NEO 6M }\end{array}$ & RX & $\begin{array}{c}\text { RX ke PIN 1 } \\
\text { arduino }\end{array}$ \\
\cline { 2 - 3 } & TX & $\begin{array}{c}\text { TX ke PIN 0 } \\
\text { arduino }\end{array}$ \\
\hline
\end{tabular}




\begin{tabular}{ccc}
\hline & GND & GND ke PIN \\
& & GND arduino \\
\cline { 2 - 3 } & VCC & VCC ke PIN \\
& & 5V arduino \\
\hline Limit Switch & PIN 1 & PIN 1 ke PIN \\
& & D4 arduino \\
\cline { 2 - 3 } & PIN 2 & PIN 2 ke \\
& & GND arduino \\
\hline
\end{tabular}

\subsection{Perancangan Software}

Pada perancangan software ini meliputi pemograman dengan menggunakan bahasa $\mathrm{C}$, agar perancangan software sistem mudah dilakukan dengan cepat. Maka terlebih dahulu membuat sebuah diagram flowchart atau diagram alir untuk menggambarkan jalannya program secara keseluruhan terhadap sebuah sistem yang akan dirancang pada alat pengamanan koper. Setelah perancangan diagram alir, maka selanjutnya adalah pembuatan program dengan bahasa $\mathrm{C}$ terhadap Arduino Uno Atmega 328. Proses pemrograman dilakukan secara bertahap hingga semua sistem dapat berjalan sesuai yang diinginkan. Berikut gambar dari flowchart sistem keseluruhan terhadap sebuah sistem yang dirancang pada alat pengaman koper dengan GPS berbasis mikrokontroler dengan output SMS dapat dilihat pada gambar 3.

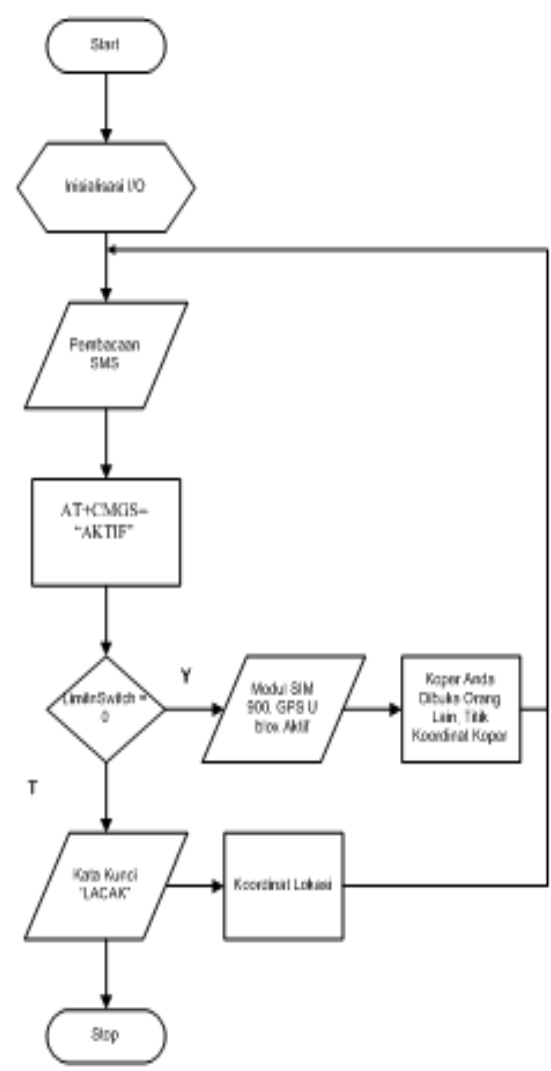

Gambar 3.Flowchart Alat keamanan koper

\section{Hasil dan Pembahasan}

Selanjutnya dilakukan pengujian untuk mengetahui apakah sistem yang dibuat telah sesuai dengan yang direncanakan. Selain untuk mengetahui apakah sistem sudah bekerja dengan baik sesuai dengan yang diharapkan. Gambar 4 merupakan alat pengamanan koper dengan GPS berbasis mikrokontroler dengan output SMS yang telah dibuat berbentuk box dan box tersebut akan dipasang pada koper.

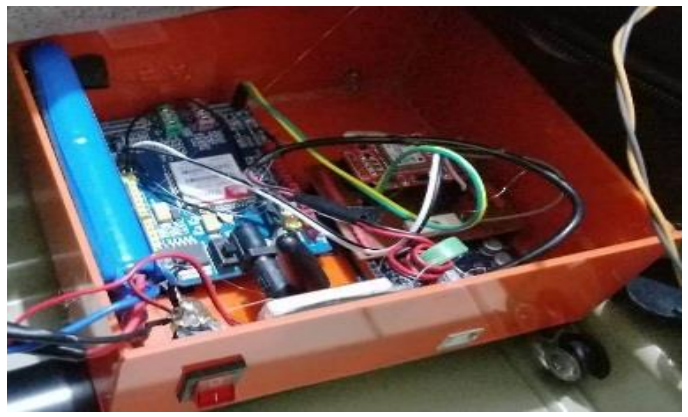

Gambar 4. alat pengamanan koper dengan GPS berbasis mikrokontroler dengan output SMS

\subsection{Pengujian Limit Switch}

Pada pengujian sensor limit switch yang diuji adalah pengukuran tegangan yang terdapat pada sensor limit switch.Tegangan yang diuji adalah pada saat limit switch berlogikan 1 dan berlogikan 0 . Pengukuran tegangan pada limit switch dapat dilihat pada tabel 2 .

Tabel 2.Hasil Pengukuran Pada Sensor Limit switch

\begin{tabular}{cc}
\hline Kondisi Pin & Tegangan \\
\hline 1 & $2.7 \mathrm{~V}$ \\
\hline 0 & $0 \mathrm{~V}$
\end{tabular}

Pada saat koper dalam keadaan tertutup maka sensor limit switch yang ada pada resleting koper akan berlogikan 1 dan tegangan yang didapat pada saat pengukuran adalah 2.7V.Tegangan yang didapat pada pengukuran limit switch ini adalah tegangan yang dihasilkan oleh pin arduino yaitu D4 dan pada saat koper dalam keadaan terbuka maka limit switch berlogikakan 0 . Pengukuan tegangan yang didapat pada limit switch adalah 0v.Tidak ada tegangan yang terdapat pada saat limit switch berlogikan 0 atau sama dengan kondisi aktif low.

\subsection{Pengujian Pada Modul SIM900}

Tujuan pengujian SIM900 dengan arduino adalah untuk mengetahui apakah program yang dibuat sesuai dengan yang diinginkan dan program tersebut sesuai dengan yang dirancang sebelumnya. Program untuk perintah mengaktifkan alat dapat dilihat pada gambar 5 . 


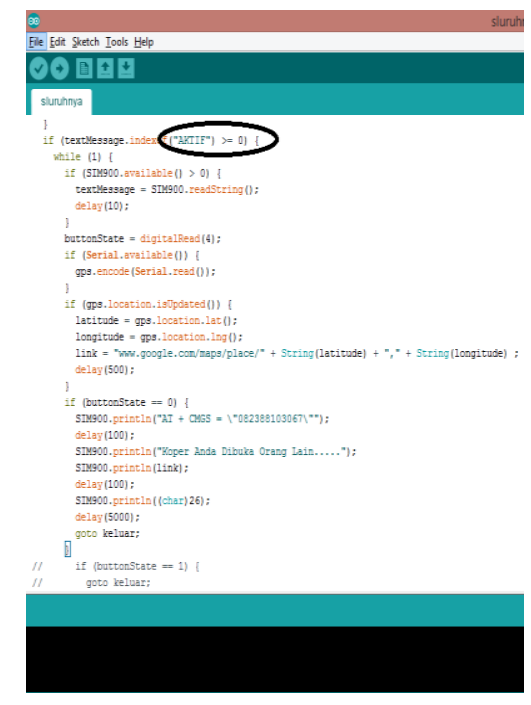

Gambar 5. Listing program pengaktifan alat

Setelah program berhasil dicompile dan di upload ke arduino maka program dapat dijalakan sesuai fungsinya.Untuk tampilan pada handphone dapat dilihat pada gambar 6.

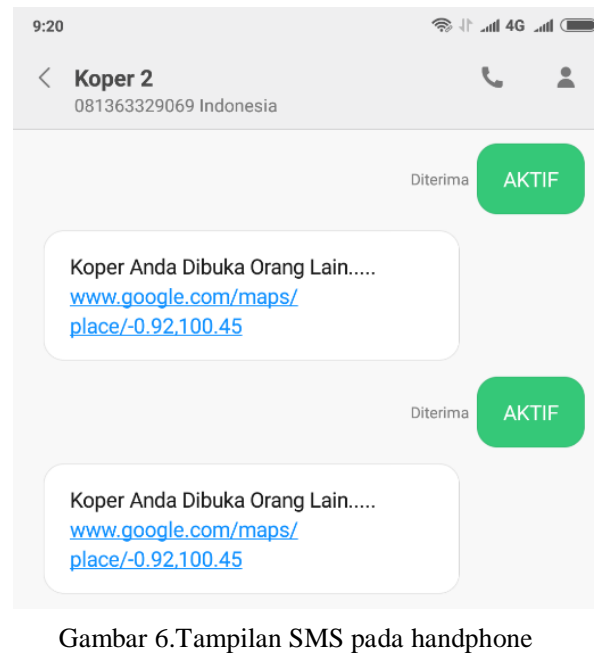

Pada saat perintah AT+CMGS "AKTIF" dilaksanakan oleh SIM900 maka SMS yang akan diterima oleh user adalah pemberitahuan bahwa koper dalam keadaaan terbuka dan juga SMS koordinat dari lokasi koper itu sendiri.

\subsection{Pengujian Modul GPS Ublox NEO 6M}

Pada pengujian modul GPS ini menggunakan smartphone android xiaomi dan modul GPS Ublox NEO $6 \mathrm{M}$ yang terpasang pada koper. Pengujian data koordinat GPS ini dibandingkan antara data koordinat GPS U-blox dengan data dari google maps. Tujuan pengujian data koordinat ini yaitu untuk mengetahui keakuratan data dari alat dengan data dari sumber lain yang sejenis. Hasil percobaan pengujian koordinat latitude pada GPS dapat dilihat pada tabel 3 .
Tabel.3 Hasil Pengujian koordinat lattitude pada GPS

\begin{tabular}{|c|c|c|c|c|}
\hline No & Tempat & $\begin{array}{c}\text { Latitude } \\
\text { Google } \\
\text { Map } \\
\end{array}$ & $\begin{array}{l}\text { Latitude } \\
\text { GPS U- } \\
\text { box } \\
\end{array}$ & $\begin{array}{l}\text { Nilai } \\
\text { Error } \\
(\%)\end{array}$ \\
\hline 1 & $\begin{array}{l}\text { Koridor Gedung } \\
\text { G (Politeknik } \\
\text { Negeri Padang) }\end{array}$ & $\begin{array}{l}- \\
0,9132 \\
65\end{array}$ & $\overline{0}, 910068$ & 0,3500626 \\
\hline 2 & $\begin{array}{l}\text { Jl. Kapalo } \\
\text { Koto } \\
\text { (Depan } \\
\text { rumah } \\
\text { No.48) }\end{array}$ & $\begin{array}{c}- \\
0,930317\end{array}$ & $\begin{array}{l}- \\
0,930 \\
340\end{array}$ & $\begin{array}{l}0,00247 \\
22\end{array}$ \\
\hline 3 & $\begin{array}{l}\text { Gerbang } \\
\text { Universit } \\
\text { as } \\
\text { andalas }\end{array}$ & $\begin{array}{l}- \\
0,9230 \\
00\end{array}$ & $\begin{array}{l}- \\
0,923297\end{array}$ & 0.0321776 \\
\hline 4 & $\begin{array}{l}\text { Jl.Koto Tuo } \\
\text { NO.8 } \\
\text { (Kapalo } \\
\text { Koto) } \\
\end{array}$ & $\begin{array}{l}-\overline{-} \\
0,921 \\
117\end{array}$ & $\begin{array}{l}- \\
0,918 \\
698\end{array}$ & $\begin{array}{c}0,26261 \\
59\end{array}$ \\
\hline 5 & $\begin{array}{l}\text { Jalan Apel } \\
\text { Raya No.79 } \\
\text { (Perum } \\
\text { Belimbing) }\end{array}$ & $\begin{array}{l}- \\
0,900 \\
173\end{array}$ & $\begin{array}{l}- \\
0,900 \\
000\end{array}$ & $\begin{array}{c}0,01921 \\
85\end{array}$ \\
\hline & \multicolumn{3}{|c|}{ Rata-rata Total Nilai Error } & 0.13330936 \\
\hline
\end{tabular}

Untuk pengujian pada koordinat longitude dapat dilihat dari tabel 4 dibawah ini :

Tabel.4 Hasil Pengujian koordinat longitude pada GPS

\begin{tabular}{|c|c|c|c|c|}
\hline No & Tempat & $\begin{array}{l}\text { Longitude } \\
\text { Google } \\
\text { Map }\end{array}$ & $\begin{array}{l}\text { Longitude } \\
\text { GPS U-box }\end{array}$ & $\begin{array}{l}\text { Nilai } \\
\text { Error } \\
(\%)\end{array}$ \\
\hline 1 & $\begin{array}{l}\text { Koridor Gedung } \\
\text { G (Politeknik } \\
\text { Negeri Padang) }\end{array}$ & $\begin{array}{l}100,4672 \\
79\end{array}$ & 100,470023 & 0,3500626 \\
\hline 2 & $\begin{array}{l}\text { Jl. Kapalo } \\
\text { Koto } \\
\text { (Depan } \\
\text { rumah } \\
\text { No.48) }\end{array}$ & 100,431568 & $\begin{array}{l}100,431 \\
650\end{array}$ & $\begin{array}{l}0,00247 \\
22\end{array}$ \\
\hline 3 & $\begin{array}{l}\text { Gerbang } \\
\text { Universit } \\
\text { as } \\
\text { andalas }\end{array}$ & $\begin{array}{l}100,4483 \\
76\end{array}$ & 100,448260 & 0.0321776 \\
\hline 4 & $\begin{array}{l}\text { Jl.Koto Tuo } \\
\text { NO.8 } \\
\text { (Kapalo } \\
\text { Koto) }\end{array}$ & $\begin{array}{l}100,445 \\
649\end{array}$ & $\begin{array}{l}100,450 \\
000\end{array}$ & $\begin{array}{l}0,26261 \\
59\end{array}$ \\
\hline 5 & $\begin{array}{l}\text { Jalan Apel } \\
\text { Raya No.79 } \\
\text { (Perum } \\
\text { Belimbing) } \\
\end{array}$ & $\begin{array}{l}100,417 \\
659\end{array}$ & $\begin{array}{l}100,420 \\
000\end{array}$ & $\begin{array}{c}0,01921 \\
85\end{array}$ \\
\hline & \multicolumn{3}{|c|}{ Rata-rata Total Nilai Error } & 0.00191826 \\
\hline
\end{tabular}

Tampilan koordinat lokasi koper yang didapatkan oleh modul GPS Ublox NEO 6M yang terpasang pada koper tersebut dapat dilihat pada aplikasi google maps yang ditampilkan pada android.Untuk tampilan koordinat koper pada aplikasi google maps dapat dilihat pada gambar 7. 


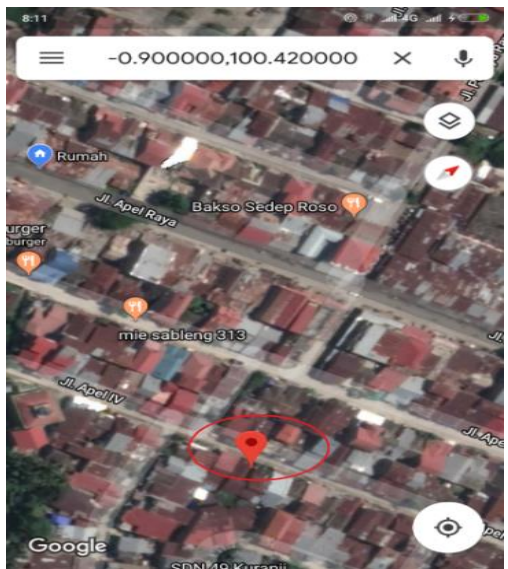

Gambar 7.Tampilan Koordinat koper pada google maps

Lingkaran merah yang ditandai pada gambar google maps merupakan titik koordinat yang menunjukan kebaradaaan dari lokasi koper.

\subsection{Analisa}

Input dari sistem ini berasal dari baterai nicd dengan tegangan 9.6V. Baterai dihubungkan langsung ke modul SIM900 melalui power regulator yang terdapat pada modul SIM900.Pada modul SIM900 tegangan input yang masuk diturunkan menjadi 5V.SIM900 dihubungkan ke mikrokontroler arduino melalui 4 buah pin yaitu RX,TX,GND dan VCC.Arduino akan terhubung dengan modul GPS dan limit switch. Limit switch yang terdapat pada resleting koper terhubung dengan pin D4 pada arduino. Pada saat Limit switch berlogikakan 1 maka Limit switch mendapat tegangan 2.7V dari arduino setelah dilakukan pengukuran,namun pada saat berlogikaan 0 tegangan pada Limit switch setelah diukur adalah 0V. Modul SIM900 yang terdapat pada koper berfungsi sebagai penerima dan pengirim SMS kepada user. Setelah dilakukan pengukuran dan pengujian pada SIM900 didapatkan kondisi bahwa pada saat pada saat mengirim data tegangan yang dihasilkan adalah sebsesar $4.5 \mathrm{~V}$ dan pada saat menerima data tegangan yang didapat pada saat dilakukan pengukuran menggunakan multimeter adalah $4.7 \mathrm{~V}$. Namun pada saat modul SIM900 tidak menerima ataupun mengirim data tegangan yang diukur pada pin RX dan TX yang terdapat pada SIM900 yaitu sebesar 3.2V.Modul SIM900 tidak akan mendapatkan sinyal jika tegangan supplay untuk modul kurang dari $5 \mathrm{~V}$.Untuk itu sebelum menggunakan SIM900 terlebih dahulu dicek tegangan yang akan menjadi input untuk modul SIM900.

Pada koper juga terdapat modul GPS Ublox NEO 6M yang berfungsi sebagai penentu koordinat posisi koper. Modul GPS akan menentukan posisi koordinat longitude dan lattitude dari koper,yang mana lattitude adalah garis bujur dan longitude adalah garis lintang.Modul GPS melalui modul SIM900 akan mengirimkan berupa titik koordinat posisi koper yang dapat diakses melalui aplikasi google maps pada android user.Dan user dapat melacak koordinat posisi koper tersebut. Pada pengujian modul GPS dilakukan pada 5 titik lokasi yang terdapat pada tabel 10 dan tabel 11.Pada saat pengujian dilakukan pada modul GPS Ublox NEO 6M, Untuk mengetahui persentase keakuratan alat pengamanan koper yang dibuat maka hasilnya dibandingkan dengan data koordinat google maps. Berdasarkan percobaan yang telah dilakukan didapatkan nilai error atau perbedaan data koordinat. Dari tabel 3 dapat dilihat bahwa nilai rata-rata error dari data koordinat latitude GPS U-blox yaitu sebesar $0.13330936 \%$. Selanjutnya pada tabel 4 dapat dilihat nilai rata-rata error dari data koordinat longitude GPS U-blox yaitu sebesar $0.00191826 \%$. Alat pengamanan koper hanya memproses pesan atau perintah yang diterima dari nomor telepon yang didaftarkan pada coding mikrokontroler. Pada saat pembacaan terhadap nomor pengirim SMS, alat menerima pesan utuh melalui SIM900 dan mencocokkan nomor pengirim dengan daftar nomor yang dikenali. Pada saat nomor tidak ada pada daftar nomor user, alat akan memberitahukan melalui terminal bahwa nomor tersebut tidak dikenali dan pesan akan langsung di hapus. Isi pesan juga harus di kenali oleh alat pengamanan koper Perintah yang dikenali untuk permintaan lokasi adalah "LACAK", jika perintah benar maka proses akan dilanjutkan dengan pembacaan lokasi. Alat akan membalas permintaan lokasi koper dengan waktu dan koordinat lokasi berupa link google maps.Berdasarkan pengujian yang telah dilakukan, alat bekerja secara maksimal pada saat berada pada kondisi outdoor. Karena GPS U-blox mendapatkan sinyal informasi lokasi dari sinyal satelit. Pada percobaan dikondisi indoor, sulit mendapatkan sinyal satelit karena terhambat oleh penghalang. Untuk mendapatkan hasil yang baik alat difungsikan pada keadaan di luar ruangan atau yang memiliki penghalang sedikit sehingga masih dapat menerima pantulan atau refleksi dari sinyal satelit untuk dapat diterima oleh GPS U-blox.

\section{Kesimpulan}

Setelah dilakukan pergujian dan pengukuran pada alat secara langsung maka dapat diambil kesimpulan :

1. Smartphone berfungsi sebagai user interface yang memberikan informasi ke SIM900 melaluli SMS atau pesan singkat untuk perintah "AKTIF" dan "LACAK".

2. Alat akan aktif ketika user mengirimkan perintah "AKTIF" melalui SMS.

3. Limit switch berlogikan 0 saat koper dalam keadaan terbuka dan berlogikakan 1 padaa saat koper dalam keadaan tertutup.

4. User masih bisa mengetahui keberadaan koper walaupun koper dalam keadaan tertutup dengan mengirimkan printah "LACAK".

\section{REFERENSI}

[1]. Marliana Sari. Protype Pengamanan Pintu Dengan Menggunakan Android Dan Embedded Sistem Nirkabel. JURNAL ILMIAH FIFO Volume VII/No. 1/Mei/2015, hal 62-74 
[2] Fina Supegina, Wahyudi. Rancang Bangun Sistem Alarm Dan [6] P. B. de Moura Oliveira. Teaching automation and control with Pintu Otomatis Dengan Sensor Gas Berbasis Arduino. Jurnal App Inventor applications. 2015 IEEE Global Engineering Education Teknologi Elektro, Universitas Mercu Buana Vol.4 No.2 Mei 2013, Conference (EDUCON). Tallinn, Estonia.

hal 44-53.

[7] Murat Karakus. Suleyman Uludag. Evrim Guler. Stephen W. Turner. Ahmet Ugur. Teaching computing and programming [3] Donzilio Antonio. Rancang Bangun Aplikasi Keamanan Brankas Berbasis Sinar Laser Dengan Mikrokontroller Arduino Nano Dan Uno R3. Jurnal SISFOKOM, Volume 02, Nomor 02, September 2013, hal $12-16$.

fundamentals via App Inventor for Android. 2012 International Conference on Information Technology Based Higher Education and Training (ITHET). Istanbul, Turkey

[4] Eni Yuliza, Toibah Umi Kalsum. Alat Keamanan Pintu Brankas Berbasis Sensor Sidik Jari Dan Passoword Digital Dengan Menggunakan Mikrokontroler Atmega 16. Jurnal Media Infotama

Vol. 11 No. 1, Februari 2015,hal 1-10.

8].Ningsih, Januarti Utari (2017) "Rancang Bangun Pelacak Lokasi Kendaraan Menggunakan G Lobal Positioning System (Gps) Berbasis Mikrokontroler". Tugas Akhir Politeknik Negeri Padang.

[9].Rafiq Arfan , Muhammad (2017) "Pengontrolan Pintu Garasi

[5] Erlina Cahya Setianingrum, Bambang Eka Purnama. Sistem Pengaman Brankas Dengan Menggunakan Handphone Berbasis Mikrokontroler AT89S51. Seminar Riset Unggulan Nasional Inoformatika dan Komputer FTI UNSA 2013, Vol 2 No 1 - Maret [10].toni Pradinata, An (2017) "Rancang Bangun Alat Pengaman 2013, hal 1-7

Mobil Barang Dengan Sms Gateway". Tugas Akhir, Politeknik Negeri Padang. 